\title{
Energy, water and environmental balance of a complex water supply system
}

\author{
M. Sambito ${ }^{1}$, V. Puleo ${ }^{2} \&$ G. Freni ${ }^{2}$ \\ ${ }^{1}$ Sering Ingegneria, Palermo, Italia \\ ${ }^{2}$ Facoltà di Ingegneria ed Architettura, Università di Enna "Kore", \\ Cittadella Universitaria, Italia
}

\begin{abstract}
The present paper describes the analysis of water and energy balance in a complex urban water supply system. The analysis was carried out employing Life Cycle Analysis (LCA) methodologies. The LCA approach was integrated with the analysis of the system energy and water balance. For a real size water supply system, based on the results of the individual LCAs, the current baseline was constructed highlighting the water, energy and environmental (in terms of $\mathrm{CO}_{2 \mathrm{eq}}$ emissions in the atmosphere) costs of supplied water. Then, three different mitigation measures have been evaluated: the first is based on energy production by installation of photovoltaic systems; the second is based on energy recovery by means of hydraulic turbines, exploiting the available pressure potential to produce energy; the third based on energy optimization of pumping stations by installing inverter systems, replacement of rotors with optimized blade profiles and installation of automation systems and self-control. Also the possibility of substituting some of the pipes of the water supply system was considered in the recovery scenario in order to reduce leakages and recovery the energy needed for leakages transport and treatment. The analysis of the results shown that energy recovery scenario is the most reliable solution even without any pipe substitution. Thanks to the recovery of energy and limiting the environmental impact of the system, the $\mathrm{CO}_{2 \text { eq }}$ production per cubic meter of supplied water was reduced from 0.41 to $0.07 \mathrm{~kg} \mathrm{CO} \mathrm{CO}_{2 \mathrm{q}} / \mathrm{m}^{3}$ of supplied water.
\end{abstract}

Keywords: life cycle assessment, scenario analysis, potable water supply, sanitation, urban water systems. 


\section{Introduction}

The analysis of environmental and energetic impact of water supply service is becoming a current issue to be tackled by the water managers. The reasons for this growing interest can be found in the search for the optimization of service running costs and in the diffusion of sustainable policies in the exploitation of natural resources.

The Life Cycle Analysis (LCA) method [1] was adopted, bringing to light an instrument that today is a sign of innovation, safeguard of the environment and economic strategy for businesses or institutions wishing to adopt a more "environmentally friendly" approach for their products and services.

LCA procedures, with regard to environment, deal with generation of air pollutants, water use, wastewater generation, energy consumption and greenhouse gas (GHG) emissions. Namely, the carbon footprint is defined as "the total amount of GHG emissions directly and indirectly caused by an activity or is accumulated over the life stage of product" [2]. Several LCA approaches can be applied for the GHG evaluations: bottom up or process analysis; top down or input-output analysis; and hybrid models [3]. An interesting review about the current carbon footprint methods of estimation is presented in [4].

In the present paper, the water, energy and environmental balance of a complex water supply system is presented. In the following after a brief review of LCA applications to water supply, the case study and the methodology are described. Then, the mitigation measures scenarios are analysed and the results discussed.

\section{Life Cycle Analysis application to water supply}

Several applications of LCA to water supply have been proposed in literature with regards to supply, treatment and water use.

As shown by Friedrich et al. [5] most of the environmental impacts are related to the energy usage in water treatment processes. Barrios et al. [6] presented the environmental and financial impact of an existing water treatment in comparison with several operational scenarios by using LCA. Nevertheless, in addition to water treatment the water extraction can be considered as relevant environmental impact due to high electricity consumption [7].

The LCA methodology was also applied for the selection of the most suitable supply solutions [8] and to analyse complex urban water supply. In particular, Friedrich et al. [9] analysed three different options such as maximising use of existing assets, recycling water and building new infrastructure. As result, for the considered case study, the construction of new infrastructure had a higher environmental burden, while the recycling of water due to maximization of the use of existing assets is proved to be the most environmentally friendly option. The environmental impacts of the construction phase of water supply network, with regards to different pipe materials, have been recently considered in SanjuanDelmas et al. [10].

Lundie et al. [11] proposed LCA as methodology for the development of strategic planning processes for water utilities. They have demonstrated the LCA 
valuable contribution in comparing several scenarios in term of environmental issues by considering at the same time financial, social and practical considerations. Further studies have also pointed out LCA as adaptable decisionmaking tool for scenarios comparison as well as technologies and prioritising interventions $[7,12,13]$.

Operational LCA methods were applied to analyse the potential environmental impacts of freshwater use or freshwater resource depletion [14]. A regionalized assessment is necessary, since the impacts of water use vary greatly as a function of location [15].

With regard to water distribution systems, Herstein et al. [16] proposed a LCA approach to minimise multiple environmental impacts, capital costs and pumping energy use by the introduction of the Environmental Impact Index [17] in the formulation of a multi-objective optimization problem.

Several authors pointed out the remarkable relationship between energy and leakages. The high level leakages are often responsible for more than $25 \%$ of the total energy consumption and, on the other hand, energy efficiency improvements could lead to $20-30 \%$ reduction of the overall water demand [18]. Often the electricity consumption is proposed as environmental indicator [5], even if some limitations have been underlined mainly in system not characterized by pumping station. A different approach, able to assess the distribution system energy efficiency also in gravity system, based on carbon footprint, is presented in Boulos and Bros [19], where the friction and discrete losses, also at the consumers tap, are converted in term of potential energy. Lundin and Morrison [20] have applied LCA for the selection of environmental sustainability indicators for urban water systems.

\section{Methodology}

In the present paper, the LCA approach aimed to GHG evaluation was integrated with the analysis of the system energy and water balance. Although LCA evaluates the environmental impact of products or processes along its entire life cycle, it can also be applied to assess only one specific stage, as in this proposed study, where only the operational stage is assessed.

In order to perform LCA, the boundaries must be selected with regard to the activities which will include in the analysis, and time period. In particular, in the present analysis was carried out on the potable water production and supply with the system boundaries being the water sources (the environment) and the urban tanks (the users). Because the aim of the paper was the comparison of different mitigation solutions, the analysis was not carried out on the whole urban water cycle (including sewer systems and waste water treatment) in order to reduce the complexity of the analysis. The analysed water supply system still includes more than 80 units composing the potable water production chain from the environment to the users.

The inventory data have been collected from Ecoinvent V 3.1 database, with national energy mix defined by the Italian Energy Authority (GSE). The use of the 
database, considering water losses, allowed for the estimation of GHG production for the whole system and for each subsystem described below.

\section{The water supply system in Palermo}

The city of Palermo is the sixth most populous in Italy with around 800,000 residents, 50,000 daily workers and 100,000 seasonal tourists. The city is located on the northern coast of Sicily and it is surrounded by sea (North) and mountains (in the other directions).

Water supply is provided by several ground (wells and springs) and surface sources (artificial reservoirs and rivers). Waters are collected by three water systems (Figure 1): the Scillato system collecting water sources on the East side of the region; the Gabriele system collecting water sources located on the Southern mountains; the Jato system collecting water sources located on the West side of the region. The average abstracted volume is equal to $142.8 \mathrm{Mm}^{3} /$ year and the average volume supplied to users is equal to $86 \mathrm{Mm}^{3} /$ year. Average water losses are in the range of $40 \%$ : the Scillato water supply system is characterised by higher losses (52.5\%); Gabriele and Jato systems are newer and characterised by lower leakage volumes (27.8\% and $24 \%$ respectively).

Details about the system and about Palermo water supply may be found in Fontanazza et al. [21-23].

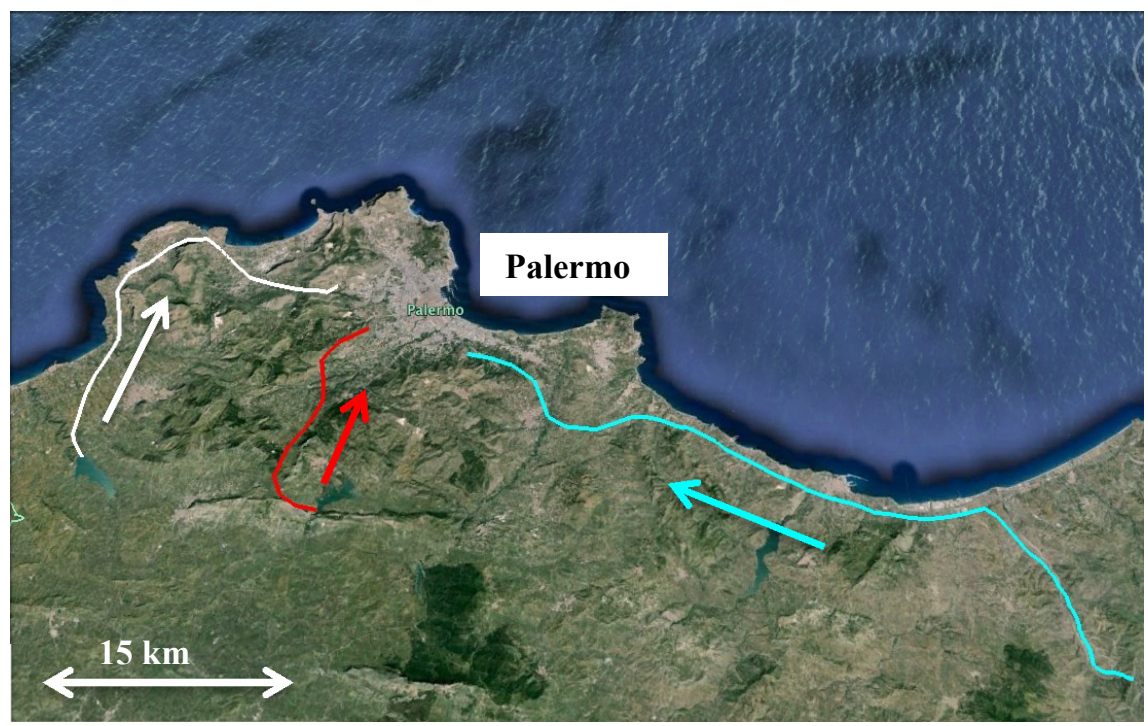

Figure 1: Water supply scheme in Palermo: the Jato system (in white); the Gabriele system (in red) and the Scillato System (in cyan). 

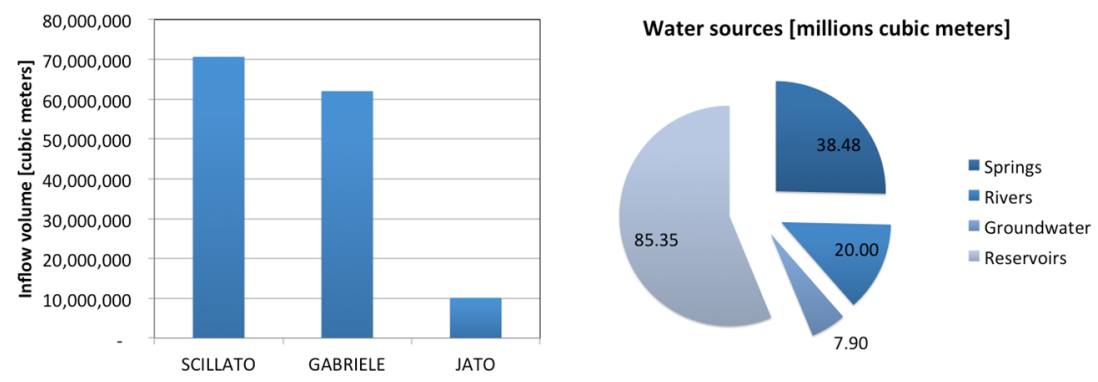

Figure 2: System inflows and origin of yearly water supply.

The current baseline showed that GHG production is mainly due to energy consumption (for pumping and treatment) and to direct production of GHG during treatment that can be neglected in the present study. The Scillato system is the more complex with 3 springs, 19 wells, 2 treatment plants (connected to 3 reservoirs) and 4 in-line pumping stations. The Gabriele system is supplied by a spring, 6 wells, a treatment plant and an inline pumping station. The Jato system is supplied by 3 wells and a treatment plant with no in-line pumps.

The total average energy consumption of the system is $1.99 * 10^{8} \mathrm{kWh}$ per year: $1.70 * 10^{8} \mathrm{kWh}$ due to the Scillato system; $0.29 * 10^{8} \mathrm{kWh}$ due to Gabriele system and $1.01 * 10^{6} \mathrm{kWh}$ due to Jato system. The Water Manager does not pay for the abstracted resource so the main operational cost is due to energy and maintenance. According to the National Energy Authority, the Italian energetic mix has an average cost of 0.08 Euros/ $\mathrm{kWh}$ and produces $0.49 \mathrm{~kg}$ eq. $\mathrm{CO}_{2}$ per $\mathrm{kWh}$ thus taking to the following production of $\mathrm{GHG}$ :

- $\quad$ Scillato system: 84052 ton eq. $\mathrm{CO}_{2}$ per year and an economic cost of 13.6 MEuros

- Gabriele system: 14650 ton eq. $\mathrm{CO}_{2}$ per year and an economic cost of 2.32 MEuros

- Jato system: 496 ton eq. $\mathrm{CO}_{2}$ per year and an economic cost of 0.08 MEuros

The present production of GHG may be evaluated in $0.41 \mathrm{~kg} \mathrm{CO} \mathrm{CO}_{2 \mathrm{e}} / \mathrm{m}^{3}$ of supplied water.

The system is characterised by high leakages and unused pressure jumps due to the elevation of springs and reservoirs with respect to the urban tanks. In fact, reservoirs around the city have an average water level between $135 \mathrm{~m}$ and $260 \mathrm{~m}$ above average sea level and springs are located at elevations ranging between $380 \mathrm{~m}$ and $110 \mathrm{~m}$. Urban tanks are located around the city at elevations ranging between $90 \mathrm{~m}$ and $50 \mathrm{~m}$ giving the possibility to exploit pressure jumps to produce energy to be used in the supply process. Moreover, leakage reduction programmes can be overseen as possible solutions to reduce the required potable water demand and thus reduce costs. 

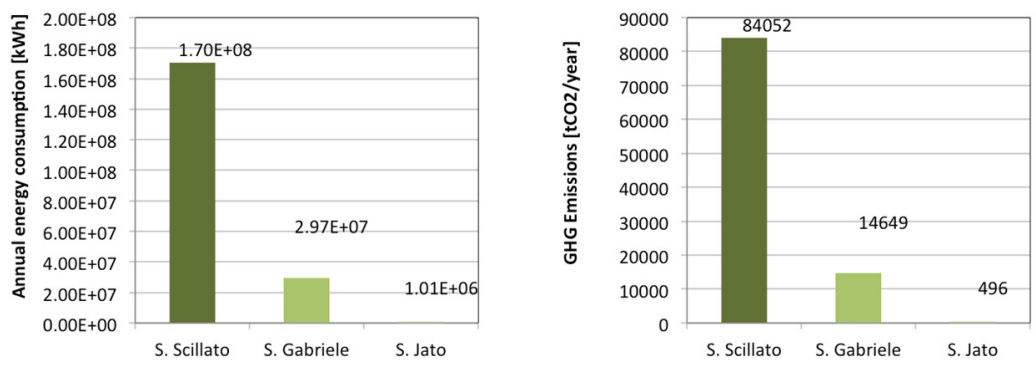

Figure 3: Current energy consumption and carbon footprint of the three supply sub-systems.

\section{Mitigation scenarios and analysis of results}

The situation of Palermo water supply system may be optimised recovering pressure energy or reducing water leakages that produce energy and economic losses. Present water losses produce an annual economic loss higher than 8 MEuros (only considering energy expenses for treatment and transport); over 20000 ton eq. $\mathrm{CO}_{2}$ per year can be avoided halving the amount of leakages in the system. Looking at the system in the present situation, three scenarios were identified:

- Scenario 1 - installation of turbines to recover pressure jump energy: Turbines are installed downstream of each pressure jump higher than 2 atm (at urban tank inlets and at the treatment plant inlet);

- Scenario 2 - substitution of a part of the Scillato pipeline: the substitution of the old steel pipe is proposed in order to reduce leakages in that system; in this scenario, the same number of turbines as Scenario 1 is introduced;

- Scenario 3 - substitution of old pumps with high efficiency ones: pumping stations are 30 years old in the average and their energetic efficiency is in the range of $60-70 \%$; new pumps and motors can reach efficiencies in the range of $80-85 \%$ thus reducing energy consumption

- Scenario 4 - installation of solar panels in the available areas of the existing treatment plants: such a solution does not require any measure on the hydraulic system and it is a common practice for reducing the operational costs of several water managers in Italy.

Scenarios were compared in terms investment costs, reduction of energy consumption and reduction of GHG emission.

In Scenario 1, 9 turbines were introduced: 2 in the Scillato system (with total installed power capacity equal to $2.2 \mathrm{MW}$ ), 4 in the Gabriele system (with total installed power equal to $4.1 \mathrm{MW}$ ) and 3 in the Jato system (with a total installed power capacity equal to $440 \mathrm{~kW}$ ). The total investment cost is equal to 18.7 MEuros. The introduction of turbines have a relevant impact on energy consumption reducing it by $55 \%$ : Scillato system energy requirement was reduced of $30 \%$ and Gabriele and Jato systems started producing more energy than consumptions. Production of GHG becomes null for the Jato and Gabriele system 

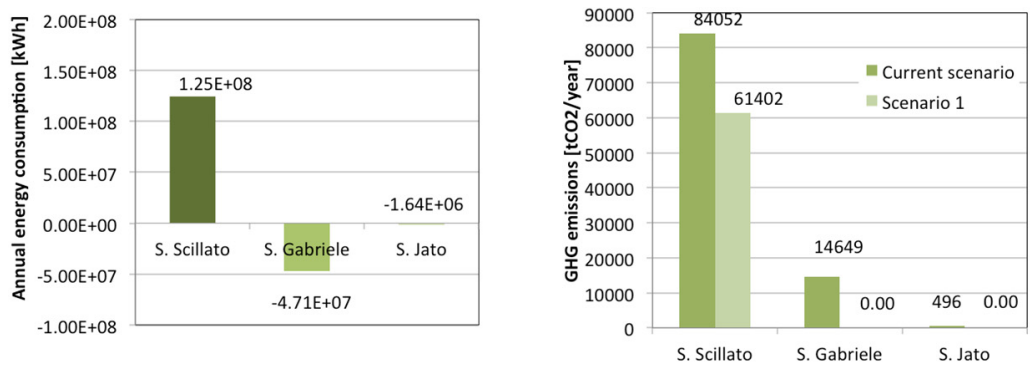

Figure 4: Energy consumption and GHG emission reduction in Scenario 1.

and it is reduced to 61402 ton eq. $\mathrm{CO}_{2}$ per year for the Scillato system. In the average the unit production of GHG is reduced to $0.26 \mathrm{~kg} \mathrm{CO} 2 \mathrm{eq} / \mathrm{m}^{3}$

In Scenario 2, the substitution of $52.4 \mathrm{~km}$ of the old steel pipe is proposed additionally to the introduction of the 9 turbines. Thanks to the substitution, flows in the main pipe are reduced of $35 \%$ and leakages are reduced to $17.2 \%$ in that system. The flow reduction is compensated by an increase in the pressure jumps at the urban tank inlets equal to $27 \%$ so the overall energy production at the Scillato turbines is reduced by $17.5 \%$. The pipe substitution takes high capital costs (61.5 MEuros) that are not compensated by the annual reduction of energy costs (1.2 MEuros per year). The small impact on energy costs is due to the fact that the reduction of flows in the system will reduce consumed and produced energy.

Being not viable at the economic level, Scenario 2 cannot be considered as an option even if the reduction of GHG production is much higher than Scenario 1 and, in the average, the unit production of GHG is reduced to $0.22 \mathrm{~kg} \mathrm{CO} 2 \mathrm{eq} / \mathrm{m}^{3}$.

Scenario 3 is aimed to the substitution of all pumps and propellers in the system with high efficiency ones. The current weighted pumping efficiency is equal to $62 \%$ and, according to the market standard, the new efficiency can be considered between $85 \%$ and $90 \%$. Considering the sole substitution of pumps and propellers, the investment cost will be 22.1 MEuros, taking a reduction of energy costs equal to 4.7 MEuros per year. In Scenario 3, in the average, the unit production of GHG is reduced to $0.21 \mathrm{~kg} \mathrm{CO} 2 \mathrm{eq} / \mathrm{m}^{3}$. The impact of the scenario on Jato system is null
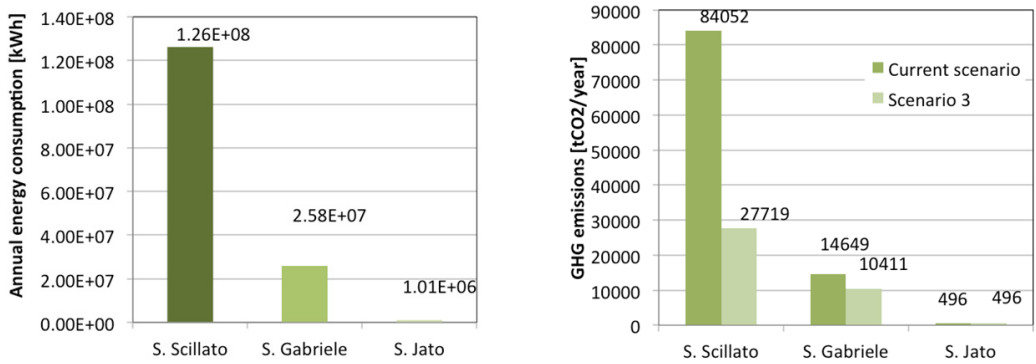

Figure 5: Energy consumption and GHG emission reduction in Scenario 3. 
because there are no pumping stations to be modified and it is low on the Gabriele system.

Finally, in Scenario 4 solar panels are introduced in the areas where treatment plants are located. The measure was applied to $2800 \mathrm{~m}^{2}$ with a production of around $600 \mathrm{kWh} / \mathrm{m}^{2}$ per year. Solar panels are not able to influence the system energy balance providing $1.68 * 10^{6} \mathrm{kWh}$ per year. As presented in figure 6 , the scenario is not providing relevant impact on both energy consumption and GHG emission. This is mainly due to the small parcel that is used to place solar panels with respect to system energy demands.

In conclusion, the sum of Scenario 1 and Scenario 3 was considered because they are the most promising offering a good combination of energy saving and energy production measures. Figure 7 shows the reduction of energy consumption
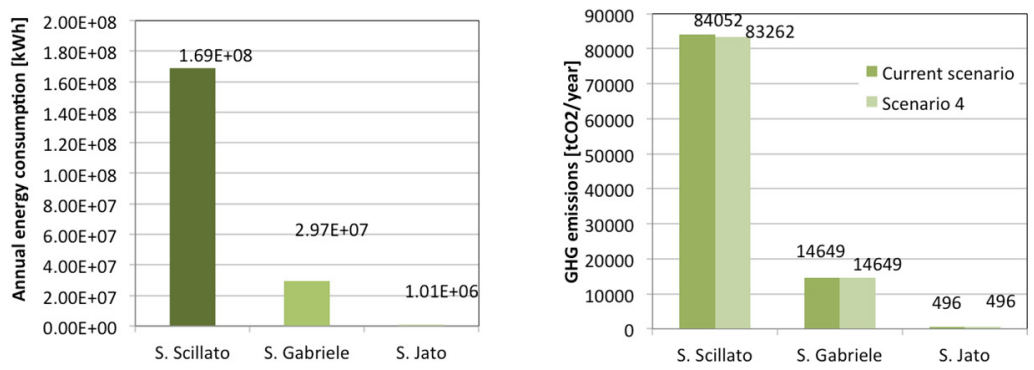

Figure 6: Energy consumption and GHG emission reduction in Scenario 4.

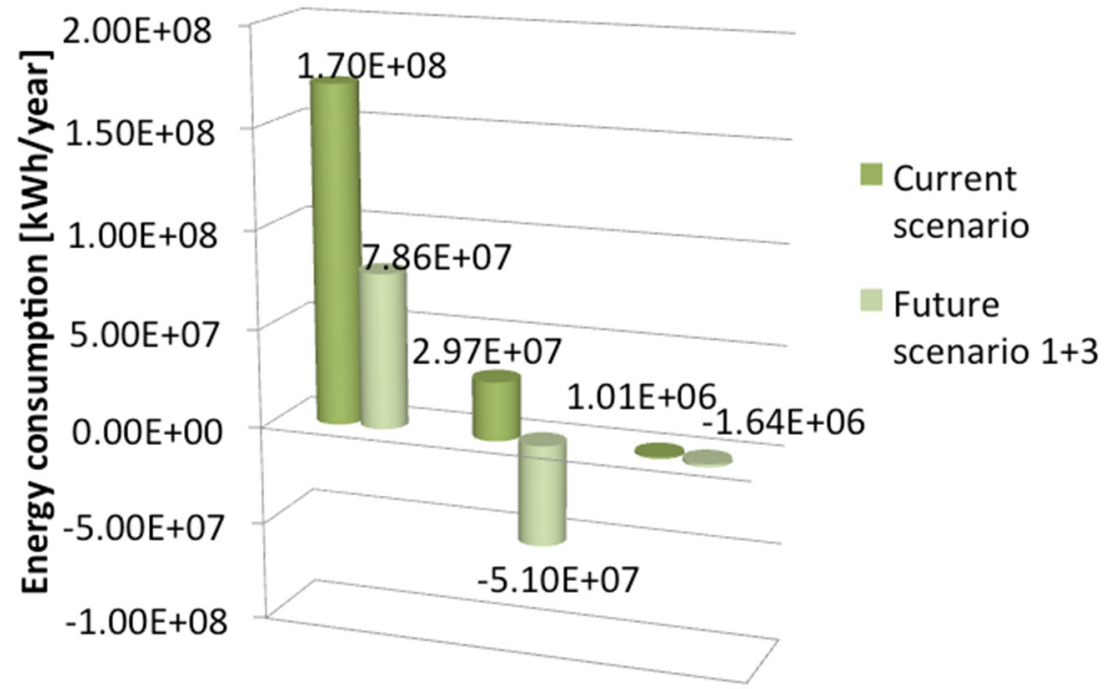

Figure 7: Comparison between energy consumption in the present condition and adopting the combination of Scenarios 1 and 3. 
and the reduction in the emission of GHG. In the average, the unit production of GHG is reduced to $0.07 \mathrm{~kg} \mathrm{CO} 2 \mathrm{eq} / \mathrm{m}^{3}$ thus taking to the reduction of $83 \%$ of the overall energy consumption of the water supply service.

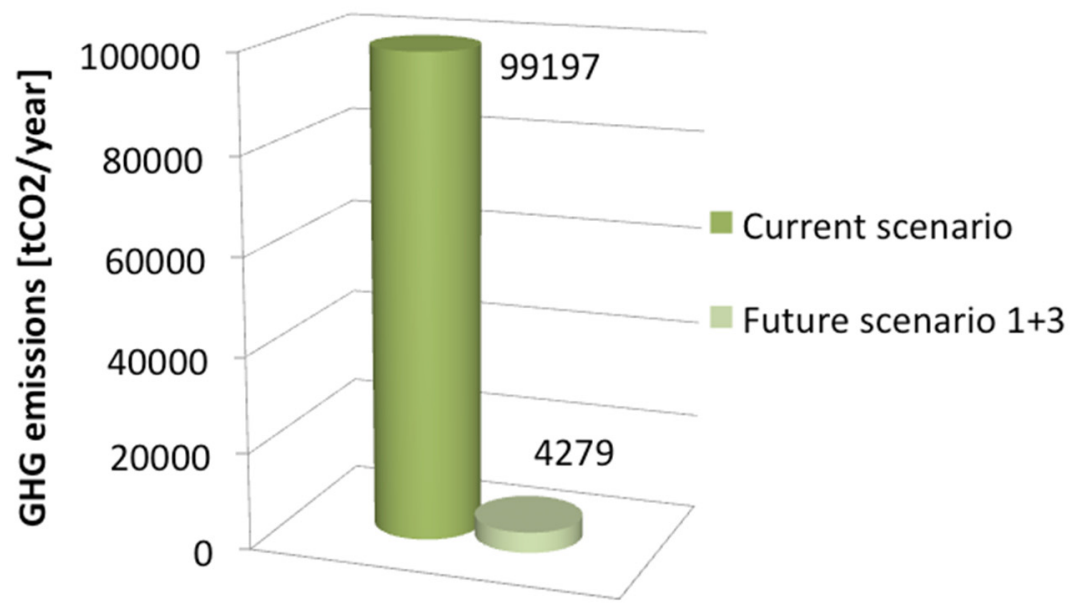

Figure 8: Comparison between GHG emission in the present condition and adopting the combination of Scenario 1 and 3.

\section{Conclusions}

In the present paper, a comprehensive LCA and economic analysis is presented to analyse possible mitigation scenarios for an urban water supply system. The methodology was applied to a complex system serving the city of Palermo counting a little less than one million inhabitants.

Scenarios were considered involving energy production, energy saving solutions and water loss reduction. Scenarios were compared with regards to capital and energy costs and GHG emission.

The present situation is characterised by a highly inefficient system in which pressure energy is lost in gravity pipes and energy is used to run pumping stations in a system leaking $40 \%$ of the supplied volumes.

A combination of energy production and energy saving solutions was in the end proposed able to reduce energy costs of $83 \%$ and taking the $\mathrm{CO}_{2 \text { eq }}$ production per cubic meter of supplied water from 0.41 to $0.07 \mathrm{~kg} \mathrm{CO}_{2 \mathrm{eq}} / \mathrm{m}^{3}$.

In general, the methodology demonstrated to be a powerful tool for comparing mitigation solutions on a multi-objective perspective involving economic and environmental aspects. The LCA approach can be then used to better detail the best scenarios identifying and prioritising the single interventions to be adopted. 


\section{Acknowledgement}

The authors would like to acknowledge the Italian Research Project PO-FESR 2007-2013 ALADIN for providing the financial support for the presented research.

\section{References}

[1] 14040, I., Environmental management - Life cycle assessment - Principles and framework, I.O.f. Standardization, Editor. 2006.

[2] 14067, I.-T., Greenhouse gases - Carbon footprint of products Requirements and guidelines for quantification and communication, I.O.f. Standardization, Editor. 2013.

[3] Peters, G.P., Carbon footprints and embodied carbon at multiple scales. Current Opinion in Environmental Sustainability, 2010. 2(4): pp. 245-250.

[4] Pandey, D., M. Agrawal, and J. Pandey, Carbon footprint: current methods of estimation. Environmental Monitoring and Assessment, 2011. 178(1-4): pp. 135-160.

[5] Friedrich, E., S. Pillay, and C.A. Buckley, The use of LCA in the water industry and the case for an environmental performance indicator. Water Sa, 2007. 33(4): pp. 443-451.

[6] Barrios, R., et al., Environmental and financial life cycle impact assessment of drinking water production at Waternet. Journal of Cleaner Production, 2008. 16(4): pp. 471-476.

[7] Lemos, D., et al., Environmental assessment of an urban water system. Journal of Cleaner Production, 2013. 54: pp. 157-165.

[8] Shrestha, E., et al., Carbon footprint of water conveyance versus desalination as alternatives to expand water supply. Desalination, 2011. 280(1-3): pp. 33-43.

[9] Friedrich, E., S. Pillay, and C.A. Buckley, Carbon footprint analysis for increasing water supply and sanitation in South Africa: a case study. Journal of Cleaner Production, 2009. 17(1): pp. 1-12.

[10] Sanjuan-Delmas, D., et al., Environmental assessment of different pipelines for drinking water transport and distribution network in small to medium cities: a case from Betanzos, Spain. Journal of Cleaner Production, 2014. 66: pp. 588-598.

[11] Lundie, S., G.M. Peters, and P.C. Beavis, Life Cycle Assessment for Sustainable Metropolitan Water Systems Planning. Environmental Science \& Technology, 2004. 38(13): pp. 3465-3473.

[12] Buckley, C., E. Friedrich, and H. von Blottnitz, Life-cycle assessments in the South African water sector: A review and future challenges. Water Sa, 2011. 37(5): pp. 719-726.

[13] Del Borghi, A., et al., Water supply and sustainability: life cycle assessment of water collection, treatment and distribution service. International Journal of Life Cycle Assessment, 2013. 18(5): pp. 1158-1168. 
[14] Bayart, J.-B., et al., A framework for assessing off-stream freshwater use in LCA. International Journal of Life Cycle Assessment, 2010. 15(5): pp. 439453.

[15] Pfister, S., A. Koehler, and S. Hellweg, Assessing the Environmental Impacts of Freshwater Consumption in LCA. Environmental Science \& Technology, 2009. 43(11): pp. 4098-4104.

[16] Herstein, L.M., Y.R. Filion, and K.R. Hall, Evaluating the Environmental Impacts of Water Distribution Systems by Using EIO-LCA-Based Multiobjective Optimization. Journal of Water Resources Planning and Management-Asce, 2011. 137(2): pp. 162-172.

[17] Herstein, L.M., Y.R. Filion, and K.R. Hall, Evaluating Environmental Impact in Water Distribution System Design. Journal of Infrastructure Systems, 2009. 15(3): pp. 241-250.

[18] Kanakoudis, V., S. Tsitsifli, and A. Papadopoulou, Integrating the Carbon and Water Footprints' Costs in the Water Framework Directive 2000/60/EC Full Water Cost Recovery Concept: Basic Principles Towards Their Reliable Calculation and Socially Just Allocation. Water, 2012. 4(1): pp. 4562.

[19] Boulos, P.F. and C.M. Bros, Assessing the carbon footprint of water supply and distribution systems. Journal American Water Works Association, 2010. 102(11): pp. 47-54.

[20] Lundin, M. and G.M. Morrison, A life cycle assessment based procedure for development of environmental sustainability indicators for urban water systems. Urban Water, 2002. 4(2): pp. 145-152.

[21] Fontanazza, C.M., Notaro, V., Puleo, V., Freni, G. The apparent losses due to metering errors: a proactive approach to predict losses and schedule maintenance. Urban Water Journal. Volume 12, Issue 3, 3 April 2015, pp. 229-239

[22] Fontanazza, C.M., Notaro, V., Puleo, V., Freni, G. Multivariate statistical analysis for water demand modeling. Procedia Engineering. Volume 89, Issue C, 2014, pp. 901-908.

[23] Fontanazza, C.M., Freni, G., La Loggia, G., Notaro, V., Puleo, V. Evaluation of the water scarcity energy cost for users. Energies. Volume 6, Issue 1, January 2013, pp. 220-234. 